\title{
BMJ Open Nurse-led medicines' monitoring in care homes study protocol: a process evaluation of the impact and sustainability of the adverse drug reaction (ADRe) profile for mental health medicines
}

Sue Jordan, ${ }^{1}$ Timothy Banner, ${ }^{2}$ Marie Gabe-Walters, ${ }^{1}$ Jane M Mikhail, ${ }^{1}$ Jeff Round ${ }^{3}$ Sherrill Snelgrove, ${ }^{1}$ Mel Storey, ${ }^{1}$ Douglas Wilson, ${ }^{1}$ David Hughes, ${ }^{1}$ the Medicines Management Group

To cite: Jordan S, Banner T, Gabe-Walters M, et al. Nurseled medicines' monitoring in care homes study protocol: a process evaluation of the impact and sustainability of the adverse drug reaction (ADRe) profile for mental health medicines. BMJ Open 2018;8:e023377. doi:10.1136/ bmjopen-2018-023377

- Prepublication history and additional material for this paper are available online. To view these files, please visit the journal online (http://dx.doi. org/10.1136/bmjopen-2018023377).

Received 4 April 2018

Revised 2 July 2018

Accepted 7 August 2018

\section{Check for updates}

(C) Author(s) (or their employer(s)) 2018. Re-use permitted under CC BY-NC. No commercial re-use. See rights and permissions. Published by BMJ.

${ }^{1}$ College of Human and Health Sciences, Swansea University, Swansea, UK

${ }^{2}$ Welsh School of Pharmacy, Cardiff University, Cardiff, UK ${ }^{3}$ Population Health Sciences, Bristol Medical School, University of Bristol, Bristol, UK

Correspondence to

Professor Sue Jordan; s.e.jordan@swansea.ac.uk

\begin{abstract}
Introduction Improved medicines' management could lead to real and sustainable improvements to the care of older adults. The overuse of mental health medicines has featured in many reports, and insufficient patient monitoring has been identified as an important cause of medicine-related harms. Nurse-led monitoring using the structured adverse drug reaction (ADRe) profile identifies and addresses the adverse effects of mental health medicines. Our study investigates clinical impact and what is needed to sustain utilisation in routine practice in care homes.
\end{abstract}

Methods and analysis This process evaluation will use interviews and observations with the participants of all five homes involved in earlier research, and five newly recruited homes caring for people prescribed mental health medicines. The ADRe profile is implemented by nurses, within existing resources, to check for signs and symptoms of ADRs, initiate amelioration and share findings with pharmacists and prescribers for medication review. Outcome measures are the numbers and nature of problems addressed and understanding of changes needed to optimise clinical gain and sustain implementation. Data will be collected by 30 observations and 30 semistructured interviews. Clinical gains will be described and narrated. Interview analysis will be based on the constant comparative method.

Ethics and dissemination Ethical approval was conferred by the National Health Service Wales Research Ethics Committee. If the ADRe profile can be sustained in routine practice, it has potential to (1) improve the lives of patients, for example, by reducing pain and sedation, and (2) assist in early identification of problems caused by ADRs. Therefore, in addition to peer-reviewed publications and conferences, we shall communicate our findings to healthcare professionals, policy-makers and sector regulators.

Trial registration number NCT03110471.
Strengths and limitations of this study

This intervention is the first simple, low-risk, lowcost, multidisciplinary strategy to check patients comprehensively for potential adverse effects of their medicines and ameliorate any harms identified.

For the last decade, some $5 \%-8 \%$ of UK unplanned hospital admissions have been caused by adverse drug reactions (ADRs), most of which were preventable. Our intervention has potential to address this situation, but sustainability needs to be tested.

- The intervention was effective in a pragmatic randomised controlled trial, but a qualitative exploration of how it embeds into routine care is needed to highlight (1) how clinical gains are achieved and (2) the barriers to and facilitators of sustained implementation.

- We are working with volunteer care homes in South West Wales, and the transferability of findings will depend on readers' interpretations of their practical adequacy and professionals' assessment of the importance of using ADRe.

\section{BACKGROUND}

The success of the WHO Third Global Patient Safety Challenge on Medication Safety will depend on effective strategies to address concerns that 'medicines sometimes cause serious harm if taken incorrectly, monitored insufficiently or as the result of errors, accidents or communication problems'. ${ }^{1}$ Meeting the challenge of insufficient monitoring will demand innovation and change to current practice. Most adverse drug reactions (ADRs) or side effects (glossary, online supplementary file 1) are due to poor monitoring, not poor prescribing. ${ }^{2-6}$ 
Preventable ADRs have proven an intractable problem over the last decade, causing $5 \%-8 \%$ of unplanned UK hospital admissions, ${ }^{78}$ costing the National Health Service (NHS) £1bn-2.5bn each year. ${ }^{9}$ The problem is at least as extensive in developing countries, at $\sim 10 \%$ of admissions. ${ }^{10}$ Most adverse drug events (ADEs) (glossary, online supplementary file 1), ADRs (glossary, online supplementary file 1) and medicines' mismanagement (including errors by patients and professionals) are preventable, ${ }^{811}$ but there are no comprehensive systematic approaches to the problem.

Some $50 \%$ of residents in UK care homes (glossary, online supplementary file 1) are prescribed mental health medicines, ${ }^{12}$ doses in care homes ${ }^{13}$ and primary care ${ }^{14}$ are often excessive, $4.8 \%-37 \%$ of older people with cognitive impairment have $\mathrm{ADRs}^{15}$ and the proportion of care home residents exposed to inappropriate medications (any) ranges from 34\% (definition from the Swedish National Board of Health and Welfare) ${ }^{16}$ to $>50 \%$ (definitions based on instruments selected by each study author). ${ }^{17}$ ADRs to mental health medicines can be life-threatening (eg, cardiac arrhythmias, cardiac hypofunction) or debilitating (eg, drug-induced Parkinsonism, ataxia, postural hypotension) or subtle and mistaken for signs of ageing or underlying pathology. They can be overlooked, leading to behaviour problems, xerostomia, constipation, poor food and/or fluid intake, tremor, restlessness, sedation, pain, double incontinence or other problems, all causing potential loss of comfort and dignity. ${ }^{18} 19$ Eighteen per cent of 13699 UK primary care incident reports and $24 \%$ of 996 deaths or serious harms recorded from 2005 to 2013 were attributed to prescription medicines (any), mainly avoidable ADRs, largely due to inadequate monitoring, communication or decision-making. ${ }^{20}$ We suggest that this care gap can be closed by formalised structured medicines' monitoring. ${ }^{1921-24}$

A consensus is emerging around overprescribing in care homes, ${ }^{13} 14162526$ and this work is now a priority for Welsh government. However, there is less agreement regarding the changes needed in routine care, ${ }^{127-29}$ and reviewers indicate that evidence supporting single-profession interventions is equivocal. ${ }^{1129-34}$ The UK Department of Health's National Dementia Strategy, launched $2009,{ }^{13}$ and Medicines and Healthcare products Regulatory Agency recommendations ${ }^{35}$ have not reduced antipsychotic prescribing, ${ }^{36}$ whereas the ADRe Profile succeeded in a randomised controlled trial (RCT). ${ }^{19}$ ADRe, formerly the West Wales ADR Profile, is available, with further information, on our website (http://www.swansea.ac.uk/adre/). It has potential to reduce costs, ${ }^{19}$ while addressing concerns over care quality, ${ }^{25272837}$ medicines' overuse, ${ }^{14}$ and the responsibility of those administering medicines to report patients' changes to prescribers, despite time constraints limiting face-to-face multidisciplinary team meetings. $^{38}$

The Food and Drug Administration warning on antipsychotic prescribing was followed by a shift towards increased use of benzodiazepines, ${ }^{39}$ and there is no evidence of benefit from long-term antidepressants in older adults ${ }^{40}$; therefore, to ensure a comprehensive approach, ADRe includes all current mental health medicines. When used by nurses, both registered nurses and nursing assistants, ADRe has improved quality of care by addressing physical health issues for all patients monitored and identifying and addressing serious adverse events in $\sim 10 \%$ of patients. Examples of previously unsuspected problems that we identified and addressed include: cardiac arrhythmias and severe hypertension, ${ }^{21}$ drug-induced Parkinsonism,${ }^{23}$ respiratory tract infections, ${ }^{41}$ pain and nausea, ${ }^{19}$ chest pain and valproate-induced pancreatitis. ${ }^{24}$ No harms have been reported from use of ADRe. We now aim to explore what is needed to optimise clinical gains and sustain implementation of ADRe in routine practice (figure 1).

\section{STUDY DESIGN AND METHODS}

This evaluation will integrate data from observations and interviews to explore clinical gains and any challenges in delivering the intervention, differences between intentions and delivery, the best way to embed medicines' monitoring into practice and relationships between ADRe, clinical contexts and processes and outcomes of care. $^{42} 43$

\section{SETTING}

We are working with 10 care homes in Abertawe Bro Morgannwg University Health Board (ABMUHB) whose management teams have volunteered to participate. This includes all five care homes involved in a previous study, who are best placed to report on sustainability, ${ }^{19}$ and five new care homes. ABMUHB is in a region of South West Wales that receives EU convergence funding because GDP is below $75 \%$ of the community mean. ${ }^{44}$ It serves a population of 525000 (33 000 aged 75-84 years and 13000 over 85 years).$^{45}$ Care homes are governed by legislation ${ }^{46}$ and regularly inspected to ensure they meet prespecified standards. ${ }^{47}$ Regularity of contact between care homes and pharmacists, consultants and general practitioners (GPs) varies across South West Wales.

\section{PARTICIPANTS}

Inclusion criteria for care homes are: providing residential or nursing care or both to $>4$ service users meeting the inclusion criteria (vi) and willing to use ADRe in routine practice. We excluded three homes participating in a previous feasibility study, as they are affiliated to a home that is already participating, which would have introduced ties into the data, ${ }^{23}$ and homes with $<5$ residents meeting the inclusion criteria or unwilling or unable to volunteer to undertake nurse-led medicines' monitoring.

The target population for mental health medicines' monitoring is people receiving at least one of: 


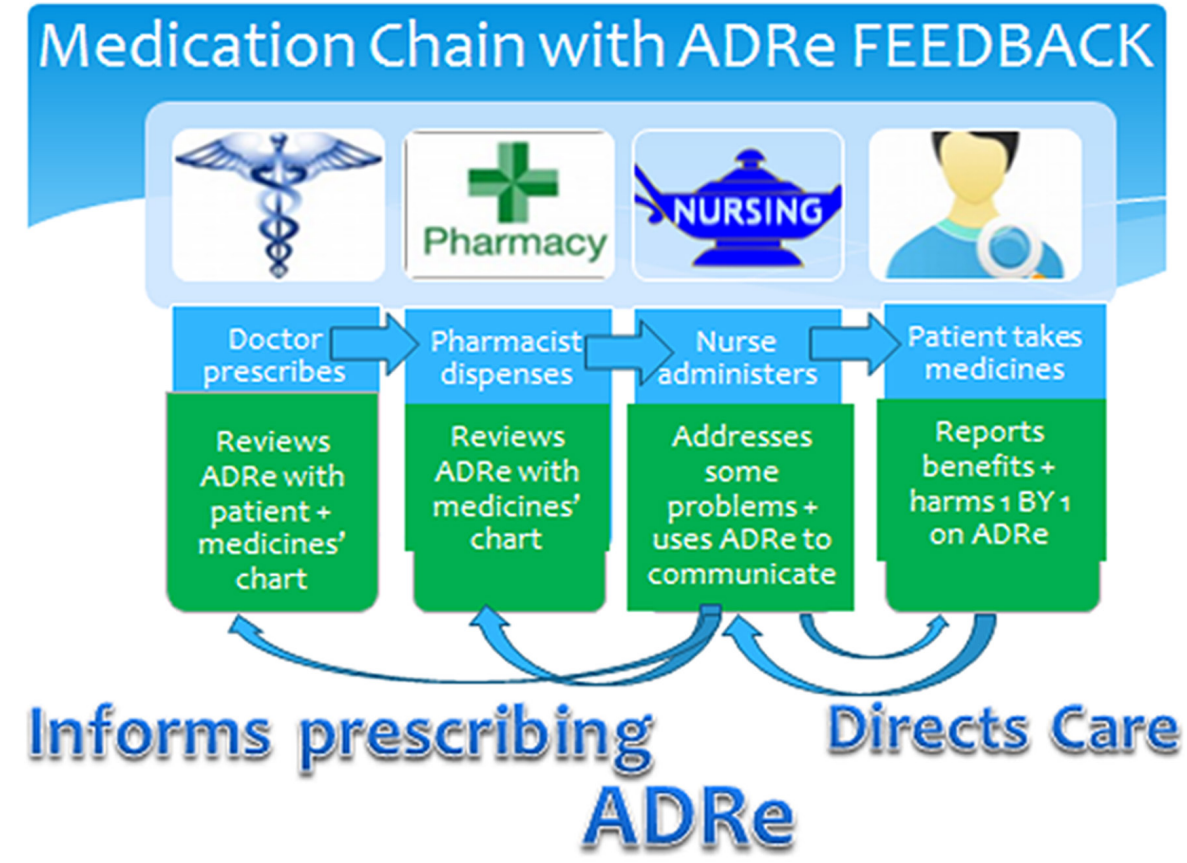

Figure 1 The medication chain.

antipsychotics, antiepileptics/mood stabilisers, antidepressants, anxiolytics or hypnotics (benzodiazepines or Z drugs). Eligibility for ADRe is based on medicines prescribed, and, previously, ${ }^{19} 23$ we found it impractical to search service users' records to determine diagnostic categories or indications for prescribing. Therefore, we are using medication administration record (MAR) charts to identify potential participants taking at least one of the mental health medicines being monitored. (In the UK, these do not record indications for prescriptions.) Three residents per care home are being observed during one completion of ADRe. Inclusion criteria are: resident at the home and expected to continue for 1 year; currently taking any of the medicines listed above; willing and able to give informed, signed consent themselves or where capacity is lacking, having a consultee (see Consent, below) willing to give advice. We exclude those not well enough to participate, as screened by their nurses, aged $<18$ years or receiving active palliative care.

Stakeholder interviews are being conducted with the study's care home leads (nurses, nurse managers, matrons or managers), residents, service users or their families, prescribers, pharmacists and key stakeholders, including strategic leads, and the care home inspectorate. ${ }^{48}$

\section{Recruitment}

All 45 eligible care homes in ABMUHB were contacted by email, and at events disseminating previous research findings, ${ }^{19}$ to seek five volunteers for this new study. Where a home expressed interest, the manager was sent detailed information. The first to respond positively were recruited, visited and trained in using ADRe until the target number was reached. Managers are asked to identify volunteer project leads and embed ADRe into routine practice before observation is arranged. Service users to be observed are recruited by their nurses, based on inclusion criteria; this involves using their professional judgement. Professionals and service users for interview are nurses and, where possible, residents or service users from the 10 care homes and stakeholders identified by snowball sampling. Respondents receive information sheets and are followed up a week later to arrange interview locations, dates and times of mutual convenience (figure 2).

\section{Sample size}

There are no fixed rules for sample size in qualitative research. ${ }^{49} 50$ The study addresses focused questions in a field where we have past experience. ${ }^{215152}$ We anticipate that 20-30 interviews and 20-30 observations will permit sufficiently powerful analyses ${ }^{53}$ : 30 transcripts will allow for 4-5 themes (see Analysis) at 50\% prevalence with 10 instances with $90 \%$ power. ${ }^{54}$ We anticipate that these numbers will achieve data saturation (in the sense of no new information being forthcoming and no new themes or categories being generated), assuming that common themes are mentioned by the diverse stakeholders; we hold open the possibility of additional interviews if important issues remain unclear.

\section{Patient and public involvement}

Our intervention and research design developed as we incorporated service users' suggestions as the work evolved. Service users were actively involved in the design and redesign of the ADRe profiles by cognitively testing and reshaping the questions and scrutinising drafts, $^{19} 23415556$ together with clinicians ${ }^{22}$ and stakeholders (patient representatives, care home staff, social workers) in interviews and focus groups. ${ }^{21} 4148$ Service users contributed to the development of this study and 


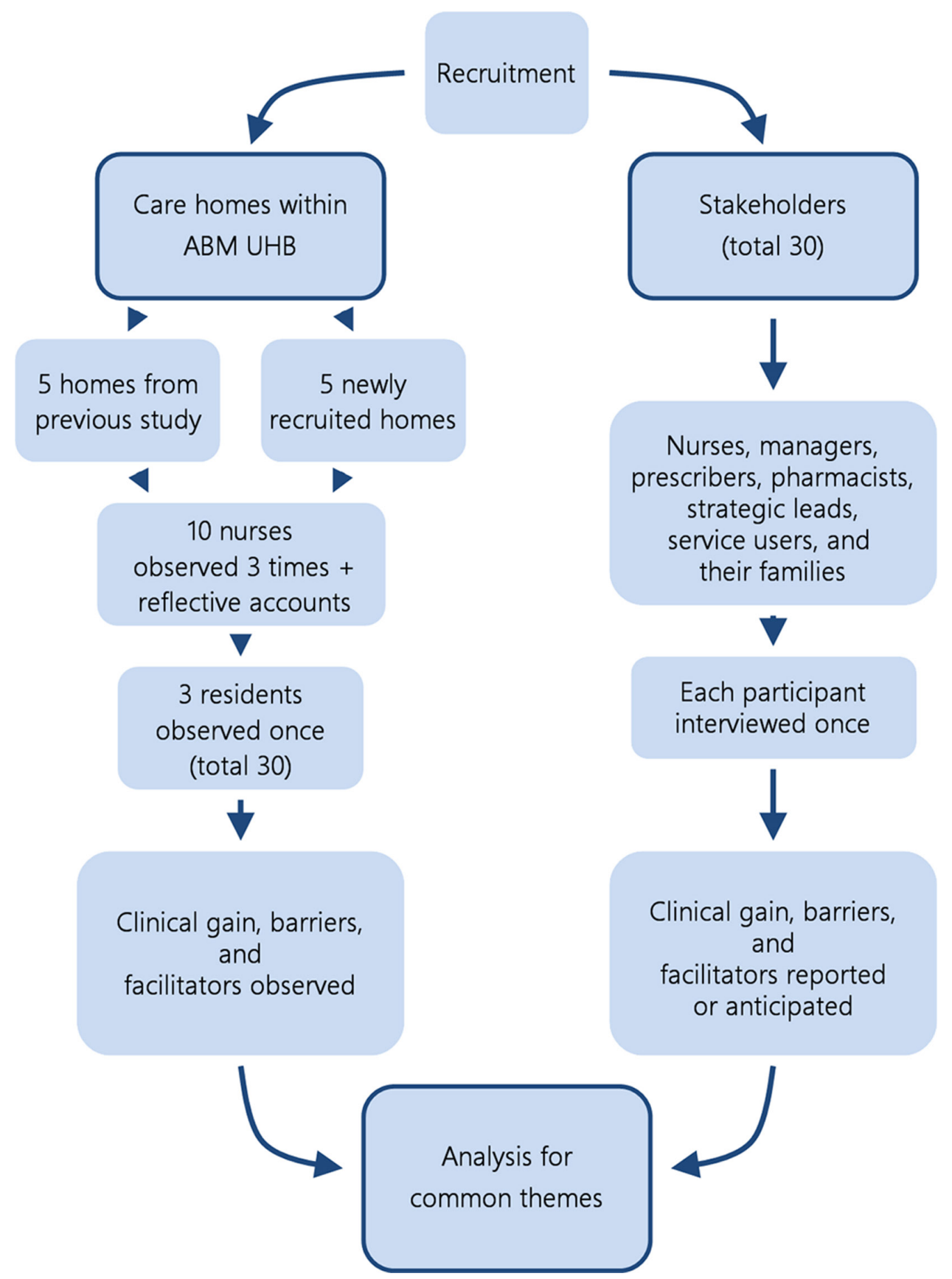

Figure 2 Participant flow diagram. ABMUHB, Abertawe Bro Morgannwg University Health Board.

will be invited to our dissemination event. Updates and research papers will be sent to participating care homes for dissemination to participating residents and their visitors.

\section{Intervention}

Structured, standardised patient questioning improves ADR reporting. ${ }^{57} \mathrm{ADRe}$ asks nurses to systematically check patients for the manifestation of itemised adverse side effects (glossary, online supplementary file 1) or undesirable effects of their mental health medicines, as listed in the British National Formulary (BNF) and manufacturers' Summaries of Product Characteristics (SmPCs), and seminal texts documenting known ADRs. ${ }^{58} 59$ We are developing a formalised approach to monitoring all patients prescribed mental health medicines, regardless of diagnostic categories. The ADRe profile for mental health medicines was introduced to address nurses' and patients' concerns that patients' ADRs were neither recognised nor communicated to prescribers. It evolved from a teaching innovation ${ }^{55}$ through before and after, ${ }^{22}{ }^{24}$ inter-rater reliability $^{56}$ and feasibility studies ${ }^{23}$ and an $\mathrm{RCT}^{19}$ to a clinically effective, evidence-based intervention. ${ }^{22-245256}$ ADRe opens dialogue with patients and provides the information needed to answer key questions:

- Are there previously unrecognised or unmonitored problems, such as postural hypotension, irregular 
heart rate, posture/movement disorders, pain or nausea that might be better managed?

- Should care plans be modified to address these problems?

- Would any of these problems be alleviated if medication doses, formulations or administration times were changed?

- Are any prescribed medicines likely causing more problems than they are alleviating?

ADRe offers a strategy to prevent ADRs becoming serious and improve care quality by: (1) regular systematic checks and documentation of problems, however subtle, listed as 'side' or 'undesirable' effects in formularies and SmPCs; (2) transfer of information to prescribers ${ }^{25} 27283738$; (3) integration with NHS, for example, contacts with prescribers (GPs and specialists), dentists and opticians $^{60}$ and (4) synergy with pharmacist reviews to optimise therapeutic regimens.

During routine care, nurses work through the list with patients, address some problems themselves and feedback to pharmacists or prescribers (see figure 1). Some ADRe items identify where additional nursing care is needed to mitigate the adverse effects of medicines, for example, drug-induced xerostomia may be limiting eating and warrant additional oral care and dental examinations, or recording tremor or ataxia may trigger reassessment of risks of falls. Other problems require discussion with prescribers or referral to specialists and help from multidisciplinary teams (for example, pain, nausea, restlessness, behaviour problems) ${ }^{19} 2252$ (figure 3, online supplementary file 2). Therefore, we adapted ADRe to enhance team working with pharmacists. ${ }^{125}{ }^{26}$ Pharmacists and prescribers do not always have time to engage fully with patients to obtain their perspectives ${ }^{61}$ or obtain details of signs and symptoms such as continence or bowel movements, particularly where patients are unable to verbalise: ADRe fills this communication gap.

Targeted questions identify 'side' or 'undesirable effects', as these signs and symptoms may indicate ADRs, ${ }^{58592}$ and merit attention regardless of aetiology. For example, tremor may indicate drug-induced Parkinsonism caused by antipsychotics or antiepileptics, but, as suggested in supporting information, alternative aetiologies warrant consideration: beta2 agonists or other stimulants, tramadol, fentanyl, hyperthyroidism, hypoglycaemia, anticholinesterases, alcohol misuse or dementia. Only careful review of medication records and patient history, usually in collaboration with pharmacist or prescriber, will identify likely causes and any candidate medicines for dechallenge. Rechallenge is not a normal practice in the UK, and specific laboratory tests are rarely available. ${ }^{63}$ ADRe also includes health promotion/ preventionadvice that is particularly pertinent to users of mental health medicines. For example, xerostomia caused by antipsychotic and other antimuscarinic medicines promotes dental caries, ${ }^{64}$ and ADRe asks nurses to check that service users have visited their dentists in the last year. Assessment of possible or likely aetiology rests with clinicians delivering care, as does the decision regarding the advisability of any dechallenge or deprescribing. Formal assessments of ADR causality ${ }^{65}$ cannot confer certainty or prove a connection or quantify a contribution ${ }^{63}$ and rarely achieve consensus. ${ }^{65}$ However, prescribers and care staff need to make practical assessments as to amelioration of problems. Therefore, we are sometimes less equivocal regarding health promotion measures and the advisability of investigating the full range of possible causes of problems. For example, where a tremor is detected, it is often worthwhile to review use of alcohol and stimulants, such as cold cures or caffeine, and consider the possibility of hypoglycaemia if antidiabetic agents are administered.

\section{'Unique selling points' and distinguishing features of ADRe}

Searches ${ }^{566-68}$ and reviews ${ }^{69} 70$ have not identified other comprehensive nurse-led instruments for checking patients' reactions to mental health medicines. ${ }^{2} 566671$ Searching English language work for 'adverse drug reactions' (as a MeSH entry term), nursing (as nurs*) and 'monitoring' in PubMed and the Cochrane library identified only two groups with empirical work in the area (Swansea and Antwerp) ${ }^{66}$ (search repeated 6.3.18). Cochrane reviews ${ }^{67}$ on optimising prescribing in care homes identified medication reviews, case-conferencing, education initiatives, decision-support technology and information transfer trials, but no structured medicines' monitoring. Other side-effect checklists include only antipsychotics or posture and movement problems, despite the prevalence of mental health polypharmacy, ${ }^{72} 73$ are designed for patient self-administration (our participants are not well enough) or the measurement of subjective beliefs, are very brief and lack guidelines for action. ${ }^{66} 6970$ Uniquely, ADRe includes estimates of change to prompt referral or actions and starts with vital signs, including postural hypotension and oxygen saturation: these have been pivotal in obtaining prescriber reviews. ${ }^{19}$ We recognise that physical health medicines, particularly cardiovascular medicines and analgesics, are important causes of ADRs, ${ }^{16}$ and ADRe's guidelines indicate this and seek to support clinical judgement in addressing the causes of problems identified. Work on decision support ${ }^{74}$ and multidisciplinary team communication ${ }^{75}$ is underway, but $\mathrm{ADRe}$ remains unique.

\section{Data collection}

We are undertaking interviews and non-participant observations with the participants of our five previous homes ${ }^{19}$ and five newly recruited care homes. We are observing nurses administering the ADRe Profiles, noting any discrepancies between 'as intended' and 'as operationalised', for example, items omitted or re-ordered and difficulties with equipment. Consistency between fieldworkers is ensured by preparation at team meetings and structured interview and observation schedules derived from earlier work. We aim for contextual and detailed descriptions of participants' experiences of the ADRe profile 


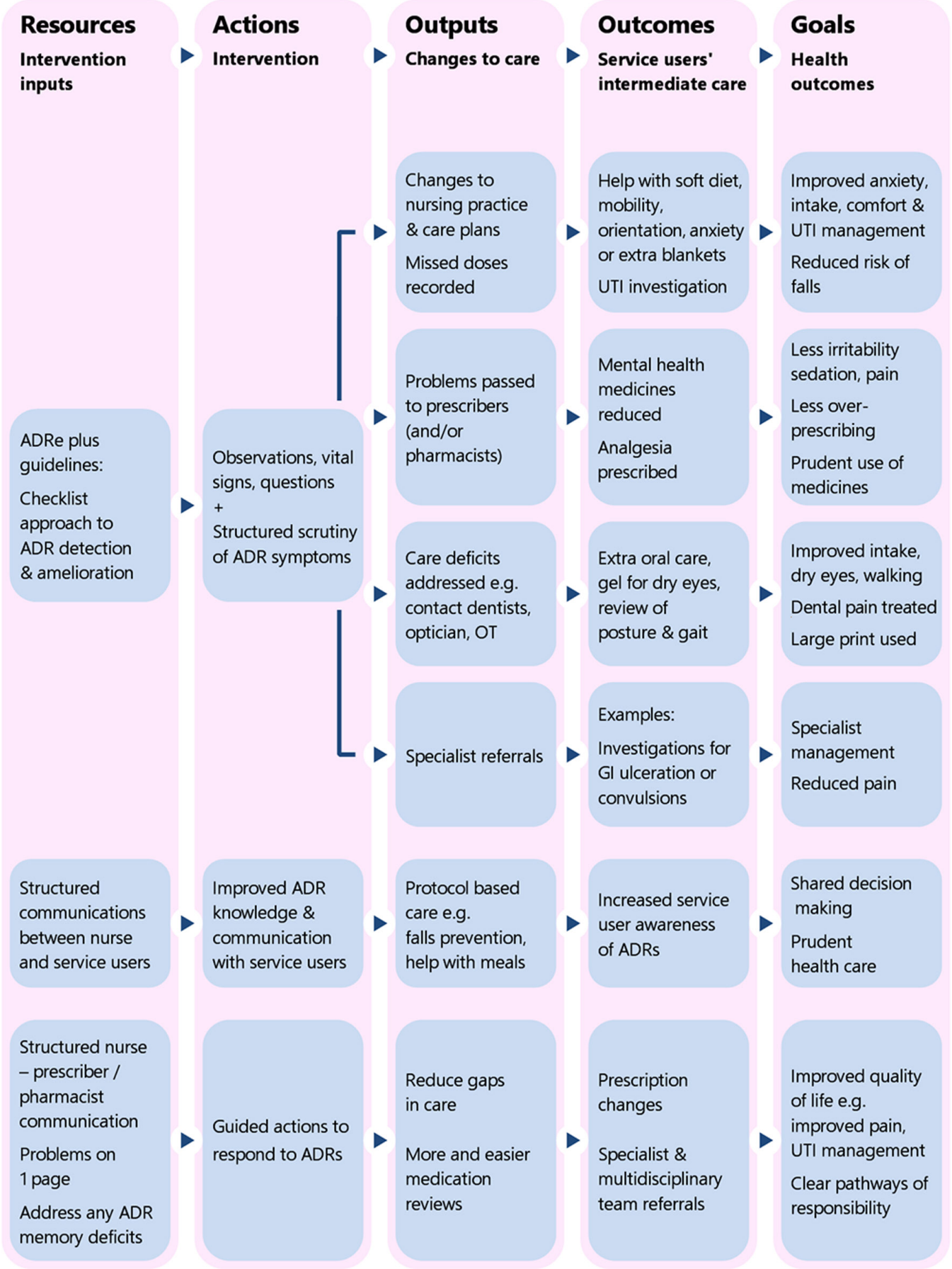

Figure 3 Logic model for ADRe: resources-actions-outputs-outcomes-goals. ADR, adverse drug reaction. Gl, gastrointestinal; OT, occupational therapist; UTI, urinary tract infenction.

and nurse-led medicines' monitoring as an innovative and incompletely understood social situation. ${ }^{76} 77$ We shall explore interest in combining ADRe with digital technologies and non-invasive patient monitoring ${ }^{78}$ and expanding to other medication groups (figure 2).

\section{Observations}

In each home, we shall observe three episodes of care involving ADRe administration and record events using templates and freehand notes, as previously described. ${ }^{22}$ We shall note how medicines' monitoring is operationalised, practical barriers and facilitators and any clinical gains and harms. ${ }^{21}$ Observations will be followed by debriefing to discuss any findings from the profile in relation to the guidelines and any suggestions for modifying practice.

Completed profiles plus the MAR charts will be passed to the study pharmacist for review. The pharmacist will make written recommendations as to how problems identified on ADRe might be addressed by changes in prescribing and raise awareness of any modifications of 
nursing care or additional monitoring needed. These are one-off reviews by a consultant pharmacist with care home expertise for the purpose of this study. Care home managers will be asked to facilitate any changes needed. For urgent matters, prescribers will be contacted directly.

\section{Interviews}

Interviewing end users as key stakeholders ${ }^{48}$ will explore experiences of ADRs, drivers of change, barriers and facilitators of medicines' monitoring to identify differing concerns and facilitate mutual understanding and joint working. ${ }^{79}$ This will determine the best way to integrate and embed medicines' monitoring in routine care, relate the profile to processes and outcomes of care and develop implementation strategies.

\section{Data analysis}

Observational data will be used to compile a record of clinical benefits and disbenefits and pharmacist recommendations.

Analysis of interviews will be based on the constant comparative method ${ }^{80}$ to identify predictors of successful adoption and any changes to profiles, working arrangements and oversight needed to embed use. This systematic, reiterative method of comparing and contrasting emerging codes, categories and concepts ensures that theoretical perspectives are embedded in the data. Interviews and observation fieldwork will be coded, categorised, analysed and closely interpreted by at least two researchers and discussed at team meetings, with consistency checks. ${ }^{81}$ The first 10 and 20 interview transcriptions will be reviewed for coding, categorisation, saturation, cases in contrast and the development of the sample.

Data from interviews, observations and pharmacist feedback will be integrated to enhance understanding, depth, rigour and validity. ${ }^{82}$ Previous themes of clinical gains, barriers, facilitators and proposals for change offer a provisional template. ${ }^{21} 2251$ Final codes and themes and data saturation will reflect collective decisions.

\section{Outcomes}

Outcome measures are clinical impact and barriers to and facilitators of sustainability.

\section{Impact}

The primary outcome of the observations is evidence of clinical impact (anticipated and actual), which will be described as: number of participants benefiting from ADRe, additional care or nursing actions and number and nature of problems addressed (including prescription changes), as noted on ADRe or reported by nurses. The outcome of pharmacist's reviews will be the number and nature of recommendations to (1) prescribers and (2) nurses made using ADRe.

\section{Sustainability}

Barriers (eg, time, interruptions, distractions) and facilitators of ADRe administration and adoption, the changes needed to embed ADRe into routine care (figure 3, online supplementary file 2) and factors that would promote or block adoption of ADRe and new technologies will be identified in thematic analyses of interviews, supported by observation data.

\section{Ethics}

Approval was obtained on 17 February 2017 from Wales Research Ethics Committee 6 who will review any protocol modifications (reference no 16/WA/0358, IRAS ID 213050). The study is sponsored by Swansea University. Written and verbal information is offered, and potential participants are given as much time as they need to decide whether to participate. Written informed consent is sought for all interviews, observations, debriefing and review of documentation or accounts. As an addition to routine nursing documentation, embedding ADRe into routine documentation falls outside the NHS Health Research Authority definition of research, ${ }^{83}$ and cluster studies do not follow the same principles as individually randomised trials in requiring individual participants' consent for non-intrusive research. ${ }^{84-87}$ Non-intrusive clinical research, including retrospective review of patient notes, where there is neither inconvenience nor hazard to patients, does not usually require expressed consent. ${ }^{88}$ The only questions ADRe asks are those that should be asked as part of routine care ${ }^{89-92}$ and confer no greater risk of harm. ${ }^{88}$ All questions relate to potential ADRs and physical health problems and are designed to ensure patient safety.

The study is not unduly invasive, in that it does not go beyond the experiences of daily life or routine medical examination, ${ }^{93}$ and all previous participants benefited. ${ }^{192-24}$ In all 10 care homes, three residents meeting the inclusion criteria are approached by their nurses and asked to consent to researchers observing administration of ADRe and reviewing their clinical records, including completed profiles and medicines charts. Signed consent is taken by registered nurses fully aware of the Mental Capacity Act $2005 .{ }^{94}$ For those without capacity to consent, consultees are approached. For many participants, the consultee is a relative in regular contact; however, for residents who have no regular visitors and rely on professional support, the consultee may be a care home clinician who knows the resident and is not involved in the research.$^{93}$ In the unlikely event that we observe breaches of the NMC code of conduct, ${ }^{95}$ these will be pursued in accordance with the code.

\section{Data handing}

All data are anonymised on collection and kept strictly confidential. Participants and care homes are assigned study numbers, and personal names only appear on consent forms. Service users' ages, sex, medicines and medical conditions are recorded. Professionals' roles, but not personal information, are recorded. Data are managed in accordance with the Data Protection Act $1998^{96}$ and the Research Governance Framework for Health \& Care Wales (2010). ${ }^{97}$ 


\section{Status of the study}

Care homes have been recruited, and data collection has started.

\section{DISCUSSION}

Prescribed medicines (any) benefit between $4 \%$ and $25 \%$ of patients, ${ }^{98}$ whereas ADRs affect $7.8 \%$ (95\% CI $7.2 \%$ to $8.4 \%)$ of patients in primary care, ${ }^{11} 11.0 \%(95 \%$ CI $5.1 \%$ to $16.8 \%$ ) of hospitalised patients, ${ }^{99}$ killing $0.25 \%,{ }^{100}$ and $4.8 \%-37 \%$ of people with cognitive impairment. ${ }^{16}$ However, systematic review indicates that healthcare professionals consistently underestimate harms and overestimate benefits of prescribed medicines. ${ }^{101}$ Consultations are often brief, informal and led by professionals with, at most, a general inquiry as to 'any side effects'. ${ }^{102} 103$ By avoiding detailed directed questions, professionals risk failing to capture patients' experiences of $\mathrm{ADRs}^{104}$ and allow ADRs to worsen, unmonitored, to the point of requiring secondary care, for example, due to falls ${ }^{105} 106$ or pneumonia. ${ }^{107} 108$ Structured monitoring facilitates social coproduction and recognition of problems that may be ADRs, as listed in the BNF and SmPCs, circumventing non-disclosure or denial by patients and professionals. ${ }^{66} 109110$ Insidious onset of problems, familiarity with the patient and overlap between some ADRs (such as falling, incontinence, sedation, confusion) and the signs and symptoms of ageing or disease militate against ADR recognition by fostering entrapment by prior expectation. ${ }^{111}$ Failure to recognise ADRs is attributable, in part, to their complexity and diversity, difficulties in remembering full lists of possible ADRs (10-20 per medicine) for multiple medicines (up to 20 per patient) and any associated deficits in education, ${ }^{112}$ knowledge ${ }^{113-116}$ or patients' and nurses' confidence in their knowledge. ${ }^{55}$ ADRs to prescribed medicines are not coincident with prescribing (they develop after the doctor has left); therefore, a mechanism is needed to transfer information $^{117}$ from patient to prescriber, across geographical and social distance. Comprehensive, formalised structured monitoring by administration of the ADRe Profile before scheduled appointments or reviews has potential to bridge this hiatus in communications and care, introduce a nursing voice into the refinement of therapeutic regimens and involve nurses in ADR management. ${ }^{118}$

\section{Systematised, protective reporting: before not after a serious ADR}

The published literature on ADRs is limited by non-disclosure of data, ${ }^{119}$ whereas ADR recognition has become reliant on expert decisions, detached from social contexts. ${ }^{110}$ Most evidence of harm comes from retrospective analyses of large databases, and each analytical method has its proponents and detractors. ${ }^{120}$ Some 5\% of serious ADRs are reported via spontaneous reporting systems, such as the iconic 'yellow card' scheme. ${ }^{121}$ Reliance on volunteer reporting renders spontaneous reporting systems vulnerable to respondent and notoriety biases. ${ }^{122} 123$

Pharmacovigilance focuses on regulators' assessments of any need to discontinue or restrict medicines and usually focuses on serious, rare and unpredictable ADRs, such as torsade, anaphylaxis or acute liver failure, rather than mundane but socially disabling ADRs, such as tremors, xerostomia, incontinence and sedation. ${ }^{124} 125$ Similarly, prescribing indicators track potentially problematic medicines, rather than patient outcomes. ${ }^{126}$ ADRe has a different focus: it is a protective strategy, aiming to prevent ADRs by regular comprehensive monitoring, embedding problem recognition in local contexts, as illustrated from earlier work (online supplementary file 2).

\section{Potential cost savings}

Decision aids in several contexts enhance professionals' perceptions of knowledge and judgement, but at the cost of extended consultation time. ${ }^{127}$ Our intervention involves nurses or care assistants, who know their patients, with support from registered nurses. We estimated $\sim £ 20$ for an initial profile completion. ${ }^{19}$ Monthly administration would therefore be offset by the estimated additional medication costs incurred by patients with ADRs (US $\$ 31.7$ or $£ 23$ per month, exchange rate: $1 \mathrm{USD} \$=0.79 \mathrm{GBP}$ as of 22 March 2018). ${ }^{128}$

ADEs (underprescribing or overprescribing of medicines) (glossary, online supplementary file 1) are responsible for $8 \%$ of healthcare spend in the USA. ${ }^{129}$ In Sweden, 9.5\% of direct healthcare costs are attributed to ADEs: each ADE incurs direct treatment costs of US $\$ 444.9$, 264-625 (£320, 10-449) for the initial episode. ${ }^{130}$ However, the average societal cost of an ADE illness is higher-US\$6235.0 (5442.8 to 7027.2) (£4481, 3911$5050)$, comprising direct costs for the illness of US\$2830.1 (2260.7 to 3399.4) (£2034, 1625-2443) (45\%) plus indirect costs for lost earnings or other commitments of US\$3404.9 (2899.3 to 3910.4) (£2447 (£2083-2809.8)). ${ }^{130}$ In the Netherlands, each preventable medication-related admission costs $€ 5461$ ( $£ 4866),{ }^{131}$ and each admission due to a fall costs $\sim £ 20 \mathrm{k},{ }^{132}$ suggesting that improved falls risk assessments, vision checks, reduction of sedatives and antipsychotics following use of ADRe could generate significant savings. Additional costs relating to pain, sedation, poor oral hygiene and poor eyesight, and their amelioration, are hard to quantify, but affect the quality of life, ${ }^{19}$ which is generally lower in those with ADRs or undertreated conditions. ${ }^{128}$ Ten completions of ADRe cost $~ £ 200$ in nursing time, and some $10 \%$ of participants have a serious ADR, that would have led to admission costing $\sim £ 4 \mathrm{k},{ }^{9131}$ prevented by ADRe. ${ }^{1922} 24$

\section{Policy fit}

Information alone rarely changes clinical practice. ${ }^{133}$ More surprisingly, consultant-led medication review, ${ }^{134}$ decision support, ${ }^{135}$ academic detailing, ${ }^{136}$ deprescribing ${ }^{137}$ and pharmacist-led interventions did not enhance clinical 
outcomes $^{30}$ or quality of life, and Cochrane reviewers found evidence for implementation to be equivocal and low quality. ${ }^{67} 68$ Some psychosocial person-centred care initiatives reduce the prescribing of antipsychotics, but are time intensive, often with ill-defined clinical outcomes and unsupported by research evidence. ${ }^{31}$ However, time, not weak evidence, is the major barrier to therapeutic drug monitoring ${ }^{138}$ and shared decision-making. ${ }^{61}$

Faced with resource constraints, increasing demand from an ageing population, concerns that social class gradients in antipsychotic prescribing ${ }^{139}$ may be compounding health inequalities, and stretched services, Welsh government's attention has focused on avoidable harm, primum non nocere, and minimising any adverse effects of care. ${ }^{66} 117$ Any harm from medicines is obfuscated by professional boundaries: prescribers (GPs and specialists) typically see residents for $7-15 \mathrm{~min}$ at review, whereas those working in care homes see the subtle, insidious adverse effects of medicines every day, but may not recognise their provenance without ADRe support. Deprescribing is often a complex decision based on detailed conversations, making repeat prescribing a quicker and easier option ${ }^{140}$ : ADRe facilitates deprescribing by gathering the information needed.

Some medicines' management strategies focus on record keeping and storage, rather than patient monitoring. ${ }^{60}$ However, other policy documents note that those administering medicines are responsible for regularly monitoring patients and reporting to prescribers any changes that may emanate from medication or if assessment of the patient indicates that the medicine is no longer suitable. ${ }^{38141}$ Mental health medicines have many adverse effects, cautions and contraindications-and few can remember them all. Therefore, ADRe obviates reliance on memory by packaging this knowledge into a format that is convenient for passing to prescribers and amenable for incorporation into electronic records. However, to work in care homes, interventions improving quality of life must be congruent with staff attitudes, priorities, time allocation, ${ }^{142}$ experience, values ${ }^{143}$ and shared understandings. ${ }^{144}$

\section{Study limitations}

Generalisation

Our study involves non-random selection of a sample of care homes in one University Health Board area in South West Wales, and further studies will be needed to confirm the transferability of findings to other local areas. We acknowledge the potential for volunteer bias in all research designs ${ }^{145}$ and the difficulties (ethical and practical) of obtaining information on the reasons for non-response to research invitations. Similarly, the pharmacist reviews are compiled by one expert pharmacist, to test the feasibility of this approach, and we do not know if less experienced pharmacists would react differently. Only policy initiatives can determine whether our findings will transfer to struggling organisations, ${ }^{37}$ as they are less likely to volunteer for research projects, and may be less likely to have sufficient staff to offer support to those withdrawing from antipsychotics. ${ }^{146}$ Participant recruitment to observations and interviews is at the discretion of nurses, and we cannot discount the possibility of selection bias. Generalisation of findings will depend on logical inferences. ${ }^{147}$ However, medicines management is a widespread problem, in urgent need of effective interventions. ${ }^{1}$

\section{Study size}

We recognise that 30 interviews encompassing the full range of stakeholders may not offer data saturation in some categories, particularly the 'hard to reach' category of national strategic leads. We estimated sample size ${ }^{5354}$ to plan ahead before applying for funding and acknowledge the limitations of this pragmatic approach, which will not affect data analysis. Our analysis will be based on common themes from multiple perspectives. When assessing practical adequacy, readers will be asked to juxtapose the clinical impact of ADRe observed here with findings of previous studies. ${ }^{192-245256}$ Resource constraints restrict each resident to a single observation, and it may not be possible to follow progress to ascertain whether recommendations have been enacted.

\section{Nurses' reporting}

ADRe relies on nurses' reports of ADRs, and many residents are non-verbal. It is, therefore, vulnerable to nurses' interpretation, and we acknowledge that nurses may under-report residents' ADRs. ${ }^{148}$ However, we are exploring how ADRe enhances delivery of care and communications and cannot discount the possibility that some problems may be misreported. Time pressures in the NHS usually limit doctor-patient contact to $7-15 \mathrm{~min}$, insufficient to review all aspects of care, although some $50 \%$ of the items on ADRe can be identified in care homes' notes, the information takes $\sim 1$ hour to retrieve. ${ }^{19}$ We therefore suggest that ADRe, despite limitations, might improve care.

\section{Prescription-based inclusion criteria}

Everyone prescribed mental health medicines is vulnerable to their adverse effects: pharmacodynamics does not respect diagnostic categories and service boundaries. Dementia diagnoses are often not recorded in the UK. ${ }^{149}$ Accordingly, our inclusion criteria centre on prescriptions and associated vulnerability to ADRs and are not restricted by diagnostic groups. Residents' medical records containing diagnoses are held by GPs and are not available in care homes.

\section{CONCLUSION}

The WHO's Third Patient Safety Challenge 'Medication Without Harm' calls for action to strengthen monitoring systems and facilitate improvements in monitoring practices. ${ }^{1}{ }^{150}$ The previous WHO Global Patient Safety Challenge was effectively met by a checklist approach. ${ }^{151}$ We hope to build a consensus around a 
similar communication approach to enhance the systems and practices of medication management. ADRe could contribute to the WHO 'Medication Without Harm' challenge, complementing and reinforcing error-reduction strategies ${ }^{71}$ and addressing problems identified by WHO,${ }^{150}$ NICE, ${ }^{8}$ DoH,${ }^{13}$ Public Health Wales, ${ }^{14}$ the Older People's Commissioner, ${ }^{25}$ the Andrews' Report ${ }^{28}$ and others. ${ }^{1}{ }^{152}$ However, political will, consensus, organisational commitment, ${ }^{14}$ morale, ${ }^{143}$ activation of a shared sense of urgency and flexible levels of engagement ${ }^{43}$ will determine whether ADRe can be sustained and ADRs addressed.

Collaborators Dr Tom Owen, Dr P Wang, Dominic Parkes, Eryl Z Maunder. Members of the Medicines Management Group (Jonathan Bidmead, Alun Toghill (service users), Karen Davies (matron), Kate McNamara, Gerwyn Panes, Victoria Warner, Centison S. Wong) supported the development of the study. The authors are grateful to computer scientists (Victoria Charvis, Tom Owens at Swansea University) and software engineer (Pulin Wang, University of Texas at Austin) for their input into the electronic devices associated with this project

Contributors SJ was the principal investigator and drafted the manuscript. TB contributed to the design and conduct of the study, assisting with analysis and review. MG-W contributed to the study design and implementation of the study. JMM contributed to the implementation and review of the study. JR contributed to the economic evaluation of the study. SS contributed to the design, analysis and implementation of the study. MS was the study coordinator and assisted with the management of the study and its implementation. DW contributed to the study design and analysis. DH contributed to the study design, conduct and analysis. All authors have been involved in the revision of the manuscript, read and approved the final manuscript to be published, agreed to be accountable for all aspects of the work in ensuring that questions related to the accuracy or integrity of any part of the work are appropriately investigated and resolved and monitored the data. TB will provide an expert review of the findings of the observations.

Funding The study is funded by Abertawe Bro Morgannwg University Health Board and sponsored by Swansea University.

Competing interests None declared.

Patient consent Not required.

Ethics approval Wales Research Ethics Committee 6 (REC6).

Provenance and peer review Not commissioned; externally peer reviewed.

Open access This is an open access article distributed in accordance with the Creative Commons Attribution Non Commercial (CC BY-NC 4.0) license, which permits others to distribute, remix, adapt, build upon this work non-commercially, and license their derivative works on different terms, provided the original work is properly cited, appropriate credit is given, any changes made indicated, and the use is non-commercial. See: http://creativecommons.org/licenses/by-nc/4.0/.

\section{REFERENCES}

1. WHO. WHO launches global effort to halve medication-related errors in 5 years. Geneva/ Bonn, 2017. (accessed 20 Aug 2017).

2. Gabe ME, Davies GA, Murphy F, et al. Adverse drug reactions: treatment burdens and nurse-led medication monitoring. J Nurs Manag 2011;19:377-92.

3. Brenner S, Detz A, López A, et al. Signal and noise: applying a laboratory trigger tool to identify adverse drug events among primary care patients. BMJ Qual Saf 2012;21:670-5.

4. Forster AJ, Murff HJ, Peterson JF, et al. Adverse drug events occurring following hospital discharge. J Gen Intern Med 2005;20:317-23.

5. Gurwitz JH, Field TS, Judge J, et al. The incidence of adverse drug events in two large academic long-term care facilities. Am J Med 2005:118:251-8.

6. Steinman MA, Handler SM, Gurwitz JH, et al. Beyond the prescription: medication monitoring and adverse drug events in older adults. J Am Geriatr Soc 2011;59:1513-20.
7. Pirmohamed M, James S, Meakin S, et al. Adverse drug reactions as cause of admission to hospital: prospective analysis of 18820 patients. BMJ 2004;329:15-19.

8. NICE Medicines and Prescribing Centre. Medicines optimisation: the safe and effective use of medicines to enable the best possible outcomes. NICE guideline. London: NICE, 2015. (accessed 20 Aug 2017).

9. Frontier Economic. Exploring the costs of unsafe care in the NHS: a report prepared for The Department of Health. $2014 \mathrm{http}: / / \mathrm{www}$. frontier-economics.com/documents/2014/10/exploring-the-costsof-unsafe-care-in-the-nhs-frontier-report-2-2-2-2.pdf (accessed 20 Aug 2017).

10. WHO. WHO Patient Safety Research. 2009 http://apps.who.int/ iris/bitstream/10665/70145/1/WHO_IER_PSP_2009.10_eng.pdf (accessed 20 August 2017).

11. Hakkarainen KM, Andersson Sundell K, Petzold M, et al. Prevalence and perceived preventability of self-reported adverse drug events - a population-based survey of 7099 adults. PLoS One 2013;8:e73166.

12. Stewart R, Hotopf M, Dewey M, et al. Current prevalence of dementia, depression and behavioural problems in the older adult care home sector: the South East London Care Home Survey. Age Ageing 2014;43:562-7.

13. Banerjee $\mathrm{S}$. The use of antipsychotic medication for people with dementia:time for action. A report for the Minister of State for Care Services. An Independent Report Commissioned for the Department of Health $2009 \mathrm{http} / / /$ webarchive.nationalarchives. gov.uk/20130104175837/http://www.dh.gov.uk/prod_consum_dh/ groups/dh_digitalassets/documents/digitalasset/dh_108302.pdf (accessed 20 August 2017).

14. Bradley P, Willson A, Buss P, et al; Achieving prudent healthcare in NHS Wales Wales: Public Health Wales, 2014. Available from. http://www.1000livesplus.wales.nhs.uk/sitesplus/documents/ 1011/Achieving\%20prudent\%20healthcare\%20in\%20NHS\% 20Wales\%20paper\%20Revised\%20version\%20\%28FINAL\%29. pdf. (accessed 20 August 2017).

15. Kanagaratnam L, Dramé $M$, Trenque $T$, et al. Adverse drug reactions in elderly patients with cognitive disorders: A systematic review. Maturitas 2016;85:56-63.

16. Sköldunger A, Fastbom J, Wimo A, et al. Impact of Inappropriate Drug Use on Hospitalizations, Mortality, and Costs in Older Persons and Persons with Dementia: findings from the SNAC study. Drugs Aging 2015;32:671-8.

17. Storms $\mathrm{H}$, Marquet $\mathrm{K}$, Aertgeerts $\mathrm{B}$, et al. Prevalence of inappropriate medication use in residential long-term care facilities for the elderly: A systematic review. Eur J Gen Pract 2017;23:69-77.

18. Jordan S. The prescription drug guide for nurses. McGraw-Hill: Maidenhead: Open University Press, 2008.

19. Jordan S, Gabe-Walters ME, Watkins A, et al. Nurse-Led medicines' monitoring for patients with dementia in care homes: a pragmatic cohort stepped wedge cluster randomised trial. PLoS One 2015; 10:e0140203.

20. Carson-Stevens A, Hibbert $\mathrm{P}$, Williams $\mathrm{H}$, et al. Characterising the nature of primary care patient safety incident reports in the England and Wales National reporting and learning system: a mixedmethods agenda-setting study for general practice. Health Services and Delivery Research 2016;4:1-76.

21. Jordan S. Managing adverse drug reactions: an orphan task. J Adv Nurs 2002;38:437-48.

22. Jordan S, Tunnicliffe C, Sykes A. Minimizing side-effects: the clinical impact of nurse-administered 'side-effect' checklists. J Adv Nurs 2002;37:155-65.

23. Jordan S, Gabe M, Newson L, et al. Medication monitoring for people with dementia in care homes: the feasibility and clinical impact of nurse-led monitoring. Scientific World Journal 2014;2014:1-11.

24. Jones R, Moyle C, Jordan S. Nurse-led medicines monitoring: a study examining the effects of the West Wales Adverse Drug Reaction Profile. Nurs Stand 2016;31:42-53.

25. Older people's Commissioner for Wales. Older People's Commissioner for Wales. A place to call home. 2014 (accessed 20 Aug 2017).

26. Thomas S, Banner T. Improving Medicines Use for Care Home Residents. Wales, Cardiff: Royal Pharmaceutical Society. (accessed 03 Apr 2018).

27. Francis R. Report of the Mid Staffordshire NHS Foundation Trust Public Inquiry. London: The Stationery Office, 2013. (accessed 20 Aug 2017).

28. Andrews J, Butler M. Trusted to Care. An independent Review of the Princess of Wales Hospital and Neath Port Talbot Hospital at Abertawe Bro Morgannwg University Health Board People: 
Dementia Services Development Centre, the People Organisation, 2014. (accessed 20 Aug 2017).

29. Page AT, Potter K, Clifford R, et al. Medication appropriateness tool for co-morbid health conditions in dementia: consensus recommendations from a multidisciplinary expert panel. Intern Med J 2016;46:1189-97.

30. Richmond S, Morton V, Cross B, et al. Effectiveness of shared pharmaceutical care for older patients: RESPECT trial findings. $\mathrm{Br} \mathrm{J}$ Gen Pract 2010;60:e10-19.

31. Fossey J, Masson S, Stafford J, et al. The disconnect between evidence and practice: a systematic review of person-centred interventions and training manuals for care home staff working with people with dementia. Int J Geriatr Psychiatry 2014;29:797-807.

32. Forsetlund L, Eike MC, Gjerberg E, et al. Effect of interventions to reduce potentially inappropriate use of drugs in nursing homes: a systematic review of randomised controlled trials. BMC Geriatr 2011;11:16

33. Holland R, Desborough J, Goodyer L, et al. Does pharmacist-led medication review help to reduce hospital admissions and deaths in older people? A systematic review and meta-analysis. Br J Clin Pharmacol 2008;65:303-16.

34. Alldred DP, Raynor DK, Hughes C, et al. Interventions to optimise prescribing for older people in care homes. Cochrane Database Syst Rev 2013:CD009095.

35. Medicines and Healthcare products Regulatory Agency, 2012. Antipsychotics: initiative to reduce prescribing to older people with dementia. https://www.gov.uk/drug-safety-update/antipsychoticsinitiative-to-reduce-prescribing-to-older-people-with-dementia (accessed 20 Aug 2017)

36. Szczepura A, Wild D, Khan AJ, et al. Antipsychotic prescribing in care homes before and after launch of a national dementia strategy: an observational study in English institutions over a 4-year period. BMJ Open 2016;6:e009882.

37. Flynn M. The Flynn Report: in search of accountability. Cardiff: Welsh Government, 2015. (accessed 20 Aug 2017).

38. All Wales Medicines Strategy Group, 2015. All Wales policy for medicines administration, recording, review, storage and disposal. http://www.awmsg.org/docs/awmsg/medman/All\% 20Wales\%20Policy\%20for\%20Medicines\%20Administration,\% 20Recording,\%20Review,\%20Storage\%20and\%20Disposal.pdf (accessed 20 Aug 2017)

39. Singh RR, Nayak R. Impact of FDA Black box warning on psychotropic drug use in noninstitutionalized elderly patients diagnosed with dementia. J Pharm Pract 2016;29:495-502.

40. Wilkinson P, Izmeth Z. Continuation and maintenance treatments for depression in older people. Cochrane Database Syst Rev 2016;9:CD006727.

41. Gabe ME, Murphy F, Davies GA, et al. Medication monitoring in a nurse-led respiratory outpatient clinic: pragmatic randomised trial of the west wales adverse drug reaction profile. PLoS One 2014;9:e96682.

42. Moore GF, Audrey S, Barker M, et al. Process evaluation of complex interventions: medical research council guidance. $B M J$ 2015;350:h1258.

43. Willis $\mathrm{CD}$, Saul $\mathrm{J}$, Bevan $\mathrm{H}$, et al. Sustaining organizational culture change in health systems. J Health Organ Manag 2016;30:2-30

44. European Commission Objective 1. Supporting development in less prosperous regions: European Commission, 2008. (accessed 04 Aug 2012).

45. Statistics Wales. Population estimates by local health boards and age Wales: Welsh Government, 2015. (accessed 03 Apr 2018).

46. Regulation and Inspection of Social Care (Wales) Act, 2016. An Act of the National Assembly for Wales https://www.legislation.gov.uk/ anaw/2016/2/contents (accessed 03 Apr 2018)

47. 2002. The Care Homes (Wales) Regulations http://www.legislation. gov.uk/wsi/2002/324/contents/made (accessed 03 Apr 2018).

48. Jordan S, Philpin S, Davies S, et al. The biological sciences in mental health nursing: stakeholders' perspectives. J Adv Nurs 2000;32:881-91.

49. Murphy E, Dingwall R, Greatbatch D, et al. Qualitative research methods in health technology assessment: a review of the literature. Health Technol Assess 1998;2:1--274.

50. Higginbottom GMA. Sampling issues in qualitative research. Nurse Res 2004;12:7-19.

51. Jordan S, Hughes D. Using bioscience knowledge in nursing: actions, interactions and reactions. J Adv Nurs 1998;27:1060-8.

52. Jordan $S$, Hughes $D$. Community teamwork is key to monitoring the side-effects of medication. Nurs Times 2000:96:39-40.

53. Malterud K, Siersma VD, Guassora AD. Sample size in qualitative interview studies: guided by information power. Qual Health Res 2015;26:1753-60.
54. Fugard AJB, Potts HWW, Ph FAJ. Supporting thinking on sample sizes for thematic analyses: a quantitative tool. Int $J$ Soc Res Methodol 2015;18:669-84.

55. Jordan S, Coleman M, Hardy B, et al. Assessing educational effectiveness: the impact of a specialist course on the delivery of care. J Adv Nurs 1999;30:796-807.

56. Jordan S, Knight J, Pointon D. Monitoring adverse drug reactions: scales, profiles, and checklists. Int Nurs Rev 2004;51:208-21.

57. Talbot J, Keisu M, Stahle L. Clinical trials - Collecting safety data and establishing the ADR Profile. In: Talbot J, Aronson JK, eds. Stephens' detection and evaluation of adverse drug reactions. 6th edn. Chichester: Wiley-Blackwell, 2012.

58. Aronson JK. Meyler's Side Effects of Drugs. In: The International Encyclopaedia of adverse drug reactions and interactions. 16th edn. Amsterdam: Elsevier Science, 2015.

59. Taylor D, Paton C, Kapur S. The Maudsley prescribing guidelines in psychiatry. 12th edn. Oxford: Wiley-Blackwell, 2015.

60. Welsh Government. Welsh Government Statutory guidance for service providers and responsible individuals on meeting service standard regulations. Cardiff: Welsh Government, 2017. (accessed 20 Aug 2017).

61. Younas M, Bradley E, Holmes N, et al. Mental health pharmacists views on shared decision-making for antipsychotics in serious mental illness. Int J Clin Pharm 2016;38:1191-9.

62. Joint Formulary Committee. British National Formulary. London: BMJ Group and Pharmaceutical Press. (accessed on 03 Apr 2018).

63. Uppsala Monitoring Centre. The use of the WHO_UMC system for standardised case causality assessment. https://www.who-umc. org/media/2768/standardised-case-causality-assessment.pdf (accessed 20 Mar 2018).

64. Plemons JM, Al-Hashimi I, Marek CL. American Dental Association Council on Scientific Affairs. Managing xerostomia and salivary gland hypofunction: executive summary of a report from the American Dental Association Council on Scientific Affairs. J Am Dent Assoc 2014;145:867-73.

65. Mouton JP, Mehta U, Rossiter DP, et al. Interrater agreement of two adverse drug reaction causality assessment methods: a randomised comparison of the liverpool adverse drug reaction causality assessment tool and the world health organizationuppsala monitoring centre system. PLoS One 2017;12:e0172830.

66. Jordan S, Vaismoradi M, Griffiths P. Adverse drug reactions, nursing and policy: a narrative review. Annals of Nursing and Practice 2016;3:1050.

67. Alldred DP, Kennedy M-C, Hughes C, et al. Interventions to optimise prescribing for older people in care homes. Cochrane Database Syst Rev 2016;16:CD009095.

68. Patterson SM, Cadogan CA, Kerse N, et al. Interventions to improve the appropriate use of polypharmacy for older people. Cochrane Database Syst Rev 2014:19:CD008165. CD008165.

69. Ashoorian D, Davidson R, Rock D, et al. A review of self-report medication side effect questionnaires for mental health patients. Psychiatry Res 2014;219:664-73.

70. Stomski NJ, Morrison P, Meyer A. Antipsychotic medication side effect assessment tools: a systematic review. Australian \& New Zealand Journal of Psychiatry 2016;50:399-409.

71. Vaismoradi M, Griffiths $\mathrm{P}$, Turunen $\mathrm{H}$, et al. Transformational leadership in nursing and medication safety education: a discussion paper. J Nurs Manag 2016;24:970-80.

72. Barnes TRE, Banerjee S, Collins N, et al. Antipsychotics in dementia: prevalence and quality of antipsychotic drug prescribing in UK mental health services. British Journal of Psychiatry 2012:201:221-6.

73. Yap KZ, Kua EH, Chan SY, et al. Improving the appropriateness of antipsychotic prescribing for Behavioral and Psychological Symptoms of Dementia (BPSD): a pilot study of the Psychotropic Use Monitoring (PUM) Program. Open J Psychiatr 2014;04:153-62.

74. Mestres Gonzalvo C, de Wit HAJM, van Oijen BPC, et al Supporting clinical rules engine in the adjustment of medication (SCREAM): protocol of a multicentre, prospective, randomised study. BMC Geriatr 2017;17:35.

75. Mahlknecht A, Nestler N, Bauer U, et al. Effect of training and structured medication review on medication appropriateness in nursing home residents and on cooperation between health care professionals: the InTherAKT study protocol. BMC Geriatr 2017;17:24.

76. Silverman D. Interpreting qualitative data. 73 . 4th edn. London: Sage Publicatons, 2011

77. Colquhoun $\mathrm{HL}$, Squires JE, Kolehmainen N, et al. Methods for designing interventions to change healthcare professionals' behaviour: a systematic review. Implement Sci 2017;12:30. 
78. Yang S, Chen Y-C, Nicolini L, et al. Cut-and-paste manufacture of multiparametric epidermal sensor systems. Adv Mater 2015;27:6423-30.

79. Smith G, Cantley C. Assessing health care: a study in organisational evaluation. Milton Keynes: Open University Press, 1985.

80. Glaser B, Strauss A. The discovery of grounded theory. Chicago: Aldine, 1967.

81. Corbin J, Strauss A. Basics of qualitative research: techniques and procedures for developing grounded theory. 3rd edn. Thousand Oaks: Sage Publications, 2008.

82. Denzin N. Triangulation 2.0. JMMR 2012;6:80-8.

83. NHS Health Research Authority (HRA). Defining Research. London: HRA, 2016. (accessed 03 Apr 2018).

84. Campbell MK, Piaggio G, Elbourne DR, et al. Consort 2010 statement: extension to cluster randomised trials. BMJ 2012;345:e5661.

85. Weijer C, Grimshaw JM, Eccles MP, et al. The Ottawa statement on the ethical design and conduct of cluster randomized trials. PLOS Med 2012;9:e1001346.

86. Taljaard M, Weijer C, Grimshaw JM, et al. The Ottawa statement on the ethical design and conduct of cluster randomised trials: precis for researchers and research ethics committees. BMJ 2013;346:f2838.

87. DiazOrdaz K, Slowther A-M, Potter R, et al. Consent processes in cluster-randomised trials in residential facilities for older adults: a systematic review of reporting practices and proposed guidelines. BMJ Open 2013;3:e003057.

88. Council of International Organisations of Medical Sciences (CIOMS)). International ethical guidelines for biomedical research involving human subjects. Geneva, Switzerland: CIOMS, 2002. (accessed 09 Jun 2017).

89. Department of Health (DoH). An organisation with a memory: report of an expert group on learning from adverse events in the NHS. London: HMSO, 2000.

90. Department of Health (DoH). Medicines and older people: national service framework. London: HMSO, 2001.

91. Audit Commission. A spoonful of sugar: medicines management in NHS hospitals. London: Audit Commission, 2001.

92. National Audit Office (NAO). A Safer place for patients: learning to improve patient safety. London: HMSO, 2005.

93. Medical Research Council (MRC). Ethics Guide Medical research involving adults who cannot consent. London: MRC, 2007. (accessed 20 Aug 2017).

94. The Stationery Office, 2005. Mental capacity act. http://www. legislation.gov.uk/ukpga/2005/9/contents (accessed 20 Aug 2007).

95. NMC. The code: Professional standards of practice and behaviour for nurses and midwives. London: NMC, 2015. (accessed 20 Aug 2017).

96. The Stationery Office, 1998. Data protection act. http://www. legislation.gov.uk/ukpga/1998/29/contents (accessed 20 Aug 2017).

97. Welsh Assembly Government. Health and Social Care, Wales, Research Governance Framework for Health \& Care Research. 2nd edn. Wales, Cardiff: Welsh Assembly Government, 2010. (accessed 20 Aug 2017).

98. Schork NJ. Personalized medicine: Time for one-person trials. Nature 2015;520:609-11

99. Alhawassi TM, Krass I, Bajorek BV, et al. A systematic review of the prevalence and risk factors for adverse drug reactions in the elderly in the acute care setting. Clin Interv Aging 2014;9:2079-86.

100. Bouvy JC, De Bruin ML, Koopmanschap MA. Epidemiology of adverse drug reactions in europe: a review of recent observational studies. Drug Saf 2015;38:437-53.

101. Hoffmann TC, Del Mar C. Clinicians' expectations of the benefits and harms of treatments, screening, and tests. JAMA Intern Med 2017;177:407-19.

102. Seale $C$, Chaplin R, Lelliott $P$, et al. Antipsychotic medication, sedation and mental clouding: An observational study of psychiatric consultations. Soc Sci Med 2007;65:698-711.

103. Quirk A, Chaplin R, Hamilton S, et al. Communication about adherence to long-term antipsychotic prescribing: an observational study of psychiatric practice. Soc Psychiatry Psychiatr Epidemiol 2013;48:639-47.

104. Nosè M, Mazzi MA, Esposito E, et al. Adverse effects of antipsychotic drugs: survey of doctors' versus patients' perspective. Soc Psychiatry Psychiatr Epidemiol 2012;47:157-64.

105. van Nieuwenhuizen RC, van Dijk N, van Breda FG, et al. Assessing the prevalence of modifiable risk factors in older patients visiting an ED due to a fall using the carefall triage instrument. Am J Emerg Med 2010;28:994-1001.
106. Petrovic M, van der Cammen T, Onder G. Adverse drug reactions in older people: detection and prevention. Drugs Aging 2012;29:453-62.

107. Gau J-T, Acharya U, Khan S, et al. Pharmacotherapy and the risk for community-acquired pneumonia. BMC Geriatr 2010;10:45

108. Paul KJ, Walker RL, Dublin S. Anticholinergic medications and risk of community-acquired pneumonia in elderly adults: a population-based case-control study. J Am Geriatr Soc 2015;63:476-85.

109. Lampela P, Hartikainen S, Sulkava R, et al. Adverse drug effects in elderly people - a disparity between clinical examination and adverse effects self-reported by the patient. Eur J Clin Pharmacol 2007;63:509-15.

110. Britten N. Adverse Drug Reactions: Societal Considerations. In: Talbot J, Aronson JK, eds. Stephens' Detection and Evaluation of Adverse Drug Reactions. 6th edn. Chichester: Wiley-Blackwell, 2012:573-84.

111. Sackett DL. Bias in analytic research. J Chronic Dis 1979;32:51-63.

112. Morrison-Griffiths S, Snowden MA, Pirmohamed M. Preregistration nurse education in pharmacology: is it adequate for the roles that nurses are expected to fulfil? Nurse Educ Today 2002;22:447-56.

113. Care Quality Commission. The State of Health Care and Adult Social Care in England 2013-14: Care Quality Commission, 2014. (accessed 20 Aug 2017).

114. Care Quality Commission The state of adult social care services 2014 to 2017. Findings from CQC's initial programme of comprehensive inspections in adult social care. Newcastle: Care Quality Commission, 2017. (accessed 20 Aug 2017).

115. Keijsers CJPW, Leendertse AJ, Faber A, et al. Pharmacists' and general practitioners' pharmacology knowledge and pharmacotherapy skills. J Clin Pharmacol 2015;55:936-43.

116. Dilles T, Elseviers MM, Van Rompaey $B$, et al. Barriers for nurses to safe medication management in nursing homes. J Nurs Scholarsh 2011;43:171-80.

117. Bradley MC, Motterlini N, Padmanabhan S, et al. Potentially inappropriate prescribing among older people in the United Kingdom. BMC Geriatr 2014;14:72.

118. Karlsson SA, Jacobsson I, Boman MD, et al. The impact of a changed legislation on reporting of adverse drug reactions in Sweden, with focus on nurses' reporting. Eur J Clin Pharmacol 2015;71:631-6.

119. Golder S, Loke YK, Wright K, et al. Reporting of adverse events in published and unpublished studies of health care interventions: a systematic review. PLoS Med 2016;13:e1002127.

120. Arnaud M, Bégaud B, Thurin N, et al. Methods for safety signal detection in healthcare databases: a literature review. Expert Opin Drug Saf 2017;16:721-32.

121. Hazell L, Shakir SA. Under-reporting of adverse drug reactions: a systematic review. Drug Saf 2006;29:385-96.

122. Pariente A, Gregoire F, Fourrier-Reglat A, et al. Impact of safety alerts on measures of disproportionality in spontaneous reporting databases. Drug Saf 2007;30:891-8.

123. de Boissieu P, Kanagaratnam L, Abou Taam M, et al. Notoriety bias in a database of spontaneous reports: the example of osteonecrosis of the jaw under bisphosphonate therapy in the French national pharmacovigilance database. Pharmacoepidemiol Drug Saf 2014;23:989-92.

124. Raine JWL, Talbot J, Aronson JK. Proactive Pharmacovigilance and risk management. In: Talbot J, Aronson JK, eds. Stephens' Detection and Evaluation of Adverse Drug Reactions. 6th edn. Chichester: Wiley-Blackwell, 2012:389-410.

125. The European Network of Centres for Pharmacoepidemiology and Pharmacovigilance (ENCePP). Guide on Methodological Standards in Pharmacoepidemiology. 6: European Medicines Agency, 2017.

126. Beuscart J-B, Pont LG, Thevelin S, et al. A systematic review of the outcomes reported in trials of medication review in older patients: the need for a core outcome set. Br J Clin Pharmacol 2017;83:942-52.

127. Stacey $\mathrm{D}$, Légaré $\mathrm{F}$, Lewis $\mathrm{K}$, et al. Decision aids for people facing health treatment or screening decisions. Cochrane Database Syst Rev 2017;19:CD001431.

128. Gyllensten $\mathrm{H}$, Rehnberg C, Jönsson AK, et al. Cost of illness of patient-reported adverse drug events: a population-based crosssectional survey. BMJ Open 2013;3:e002574.

129. Aitken MV S. Avoidable costs in US Healthcare. Parsippany, NJ, USA: IMS Institute of Healthcare Informatics, 2013. (accessed 20 Aug 2017).

130. Gyllensten H, Hakkarainen KM, Hägg S, et al. Economic impact of adverse drug events - a retrospective population-based cohort Study of 4970 Adults. PLoS One 2014;9:e92061. 
131. Leendertse AJ, Van Den Bemt PMLA, Poolman JB, et al. Preventable hospital admissions related to medication (HARM): cost analysis of the HARM study. Value Health 2011;14:34-40.

132. Burns ER, Stevens JA, Lee R. The direct costs of fatal and nonfatal falls among older adults - United States. J Safety Res 2016;58:99-103.

133. Corbett A, Stevens J, Aarsland D, et al. Systematic review of services providing information and/or advice to people with dementia and/or their caregivers. Int $J$ Geriatr Psychiatry 2012;27:628-36.

134. Ballard C, Orrell M, Sun Y, et al. Impact of antipsychotic review and non-pharmacological intervention on health-related quality of life in people with dementia living in care homes: WHELD-a factorial cluster randomised controlled trial. Int J Geriatr Psychiatry 2017;32.

135. Mestres Gonzalvo C, Milosevic V, van Oijen BPC, et al. The use of an electronic clinical rule to discontinue chronically used benzodiazepines and related Z drugs. Eur J Clin Pharmacol 2018;74:227-31.

136. Desveaux L, Saragosa M, Rogers J, et al. Improving the appropriateness of antipsychotic prescribing in nursing homes: a mixed-methods process evaluation of an academic detailing intervention. Implementation Science 2017;12:71.

137. Page AT, Clifford RM, Potter $\mathrm{K}$, et al. The feasibility and effect of deprescribing in older adults on mortality and health: a systematic review and meta-analysis. Br J Clin Pharmacol 2016;82:583-623.

138. Law S, Haddad PM, Chaudhry IB, et al. Antipsychotic therapeutic drug monitoring: psychiatrists' attitudes and factors predicting likely future use. Therapeutic Advances in Psychopharmacology 2015;5:214-23.

139. Marston L, Nazareth I, Petersen I, et al. Prescribing of antipsychotics in UK primary care: a cohort study. BMJ Open 2014;4:e006135.

140. McGrath K, Hajjar ER, Kumar C, et al. Deprescribing: a simple method for reducing polypharmacy. J Fam Pract 2017;66:436-45.

141. Welsh Government. National minimum standards for care home for older people. Cardiff: Welsh Government, 2004. (accessed 20 Aug 2017).
142. Lawrence V, Fossey J, Ballard C, et al. Improving quality of life for people with dementia in care homes: making psychosocia interventions work. Br J Psychiatry 2012;201:344-51.

143. Lawrence V, Fossey J, Ballard C, et al. Helping staff to implement psychosocial interventions in care homes: augmenting existing practices and meeting needs for support. Int J Geriatr Psychiatry 2016;31:284-93.

144. Grant A, Dreischulte T, Guthrie B. Process evaluation of the datadriven quality improvement in primary care (DQIP) trial: active and less active ingredients of a multi-component complex intervention to reduce high-risk primary care prescribing. Implement Sci 2017;12:4.

145. Jordan S, Watkins A, Storey M, et al. Volunteer bias in recruitment, retention, and blood sample donation in a randomised controlled trial involving mothers and their children at six months and two years: a longitudinal analysis. PLoS One 2013;8:e67912.

146. Cousins JM, Bereznicki LR, Cooling NB, et al. Prescribing of psychotropic medication for nursing home residents with dementia: a general practitioner survey. Clin Interv Aging 2017;12:1573-8.

147. Mitchell JC. Case and situation analysis. Sociol Rev 1983;31:187-211.

148. Dilles T, Van Rompaey B, Van Bogaert P, et al. Resident and nurse reports of potential adverse drug reactions. Eur J Clin Pharmacol 2015;71:741-9.

149. Crowther GJ, Bennett MI, Holmes JD. How well are the diagnosis and symptoms of dementia recorded in older patients admitted to hospital? Age Ageing 2017;46:112-8.

150. WHO, 2017. Medication without harm. http://apps.who.int/iris/ bitstream/10665/255263/1/WHO-HIS-SDS-2017.6-eng.pdf?ua=1\& ua=1 (accessed 20 Aug 2017).

151. de Vries EN, Ramrattan MA, Smorenburg SM, et al. The incidence and nature of in-hospital adverse events: a systematic review. Qual Saf Health Care 2008;17:216-23.

152. Care Quality Commission, 2016. Regulation 12: Safe care and treatment. Health and Social Care Act 2008 (Regulated Activities) Regulations 2014. http://www.cqc.org.uk/content/regulation-12safe-care-and-treatment\#guidance-links (accessed 20 Aug 2017). 